\title{
EDUCAÇÃO PERMANENTE EM SAÚDE NA ESTRATÉGIA SAÚDE DA FAMÍLIA: REFLEXÕES A PARTIR DO EXISTENCIALISMO E DA EDUCAÇÃO LIBERTADORA
}

\author{
Janine Moreira (UNESC)* \\ Ana Paula Macan Damiani (FVA)** \\ Caroline Scussel***
}

\begin{abstract}
RESUMO
O texto problematiza a educação permanente dos profissionais da saúde da Estratégia Saúde da Família (ESF) a partir do entendimento de educação permanente de Emerson Elias Merhy, Laura Feuerwerker e Ricardo Ceccim, da concepção filosófica/psicológica existencialista de Jean-Paul Sartre e da teoria educativa libertadora de Paulo Freire. Debate a questão: em que medida a formação em serviço dos profissionais de saúde da ESF possibilita sua viabilização enquanto pessoas críticas, autoras de suas práticas no seu processo de trabalho? Os dados empíricos foram gerados em uma pesquisa de abordagem qualitativa, a partir de entrevistas semiestruturadas com 09 enfermeiras e 17 técnicas de enfermagem de 10 ESF do município de Criciúma, sul do estado de Santa Catarina. A formação oferecida é pontual, com assuntos voltados para atualização ou para facilitar o cumprimento das metas estabelecidas. Existe espaço para discussão, mas como manifestação de dúvidas e trocas de experiências, sem que esteja presente o elemento da reflexão crítica sobre o cotidiano do trabalho realizado. Tampouco é problematizada a lógica empresarial que invade o campo da saúde pública. Esta formação não viabiliza a constituição de pessoas críticas, constituindo-se em uma educação continuada, de características bancárias, e na alienação da liberdade.

Palavras-chave: Educação permanente em saúde. Estratégia Saúde da Família. Liberdade. Educação libertadora.

\section{ABSTRACT \\ CONTINUING HEALTH EDUCATION IN THE FAMILY HEALTH STRATEGY: REFLECTIONS FROM THE VIEWPOINT OF EXISTENTIALISM AND EDUCATION FOR LIBERATION}

The present article discusses the continuing education of health professionals of the Family Health Strategy (FHS), based on the understanding of continuing education

\footnotetext{
* Doutora em Psicopedagogia pela Universidade de Córdoba - Espanha. Docente Permanente do Mestrado em Educação e do Curso de Psicologia da Universidade do Extremo Sul Catarinense (UNESC). Líder do Grupo de Pesquisa Educação, Saúde e Meio Ambiente (UNESC). E-mail: jmo@unesc.net

*** Mestre em Educação pela Universidade do Extremo Sul Catarinense (UNESC). Docente Tempo Parcial na Faculdade do Vale do Araranguá (FVA). Membro do Grupo de Pesquisa Educação, Saúde e Meio Ambiente (UNESC). E-mail: enfmacan@ hotmail.com

${ }^{* * *}$ Graduada em Psicologia pela Universidade do Extremo Sul Catarinense (UNESC). Psicóloga no Centro de Desenvolvimento e Integração Humana Simone de Beauvoir. Membro do Grupo de Pesquisa Educação, Saúde e Meio Ambiente (UNESC). E-mail: scusselcaroline@gmail.com
} 
by Emerson Elias Merhy, Laura Feuerwerker and Ricardo Ceccim, the philosophical/ psychological existentialist conception by Jean-Paul Sartre, and the education for liberation theory by Paulo Freire. The article addresses the following question: to what extent in-service training of the FHS health professionals enables their viability as critical people, authors of their practices in their work process? Empirical data was generated in a qualitative research, through the use of semi-structured interviews with nine nurses and 17 nursing technicians working in 10 FHS located in Criciúma, a city situated in the south of Santa Catarina. The training offered is limited, with issues selected in order to face daily problems or to facilitate the attainment of specific goals. There is room for discussion, but as an expression of doubt and exchange of experiences only, without critical reflection regarding the everyday work. Besides, the business logic that invades the field of public health is not confronted. This training does not accomplish the formation of critical people and seems to characterize a continuing education marked by banking aspects and alienation.

Keywords: Permanent health education. Family Health Strategy. Freedom. Education for liberation.

\section{RESUMEN}

\section{EDUCACIÓN PERMANENTE PARA LA SALUD EN EL ESTRATEGIA SALUD DE LA FAMILIA: REFLEXIONES DESDE EL EXISTENCIALISMO Y LA EDUCACIÓN LIBERADORA}

El texto problematiza la educación permanente de los profesionales de la salud de la Estrategia Salud de la Familia (ESF) a partir del entendimiento de la educación permanente de Emerson Elias Merhy, Laura Feuerwerker y Ricardo Ceccim, de la concepción filosófica/psicológica existencialista de Jean-Paul Sartre y de la teoría educativa liberadora de Paulo Freire. Debate la cuestión: ¿en qué medida la formación en servicio de los profesionales de la salud de la ESF posibilita su viabilización como personas críticas, autoras de sus prácticas en su proceso de trabajo? Los datos empíricos fueron generados en una investigación de abordaje cualitativa, a partir de entrevistas semiestructuradas con 09 enfermeras y 17 técnicas de enfermería de 10 ESF del municipio de Criciúma, sur del estado de Santa Catarina. La formación ofrecida es puntual, con asuntos direccionados para la actualización o para facilitar el cumplimiento de metas establecidas. Existe espacio para discusión, pero como manifestación de dudas y cambios de experiencias, sin que esté presente el elemento de la reflexión crítica sobre lo cotidiano del trabajo realizado. Tampoco es problematizada la lógica empresarial que invade el campo de la salud pública. Esta formación no viabiliza la constitución de personas críticas, constituyéndose en una educación continuada, de características bancarias, y en la alienación de la libertad.

Palabras clave: Educación permanente en salud. Estrategia Salud de la Familia. Libertad. Educación liberadora.

\section{Introdução}

A atuação dos profissionais de saúde no âmbito da atenção básica pode ser caracterizada como assistencial e educativa. A assistência são as ações realizadas no cuidado à saúde a partir das especificidades de cada profissão. A educação são as ações mais conhecidas como "orientadoras" do cuidado à 
saúde. Contudo, partindo-se do entendimento que educar não se resume a orientar, uma vez situar-se no âmbito da formação humana, a prática educativa em saúde ganha contornos mais abrangentes, o que, paralelamente, leva a um compromisso maior para com ela. Se educar é formar, então quem forma necessita perguntar-se: formar quem para o quê? Abre-se a necessidade de se questionar de que forma a pessoa a quem se dirige a ação de educar é vista pelo educador, assim como a intencionalidade do ato educativo. Mesmo que estes questionamentos nem sempre sejam elaborados por quem age no sentido de educar, eles permanecerão sendo fundantes da ação educativa. Portanto, o melhor que se pode fazer é trazê-los à discussão. "Ela [a história] demonstra que as circunstâncias fazem os homens tanto quanto os homens fazem as circunstâncias", diziam Marx e Engels (1974 apud EAGLETON, 1999, p. 18). Este entendimento é retomado por Jean-Paul Sartre ao discutir o conceito de liberdade, vinculado à noção de engajamento. A educação é sempre um ato político, dizia Paulo Freire ao defender uma educação libertadora, transformadora da realidade opressora.

A Educação Permanente em Saúde (EPS) é uma ação formativa dos profissionais de saúde, a partir do entendimento de que formação ocorre por toda uma vida. $\mathrm{Na}$ área da saúde costuma-se diferenciar educação continuada (EC) de educação permanente (EP). Em nosso entendimento, a educação continuada é caracterizada como a educação bancária de Paulo Freire, e a educação permanente como sua educação libertadora. Para Emerson Elias Merhy, Laura Feuerwerker e Ricardo Ceccim (2006), a educação permanente em saúde deve ser uma estratégia para que os profissionais de saúde cheguem a sua condição de autores de sua história, na resolução das questões advindas do cotidiano do trabalho, a partir da reflexão crítica.

No entanto, em geral, a formação que esses profissionais recebem em serviço restringe-se a atualizações de conteúdos e orientações/prescrições de como atuar na prática, assim como a atuação educativa em saúde dos profissionais para com os usuários dos serviços na atenção básica também fica restrita a orientações normativas. Entretanto estas ações entram em conflito com a proposta do Sistema Único de Saúde (SUS) e da Estratégia
Saúde da Família (ESF), situadas no horizonte da democratização da saúde, o que implica não somente o acesso universal aos serviços, mas a democratização das decisões e dos espaços cotidianos.

Compreendemos que a teoria filosófica/psicológica existencialista de Jean-Paul Sartre (França, 1905-1980) e a teoria educativa libertadora de Paulo Freire (Brasil, 1921-1997) nos fornecem bases para refletirmos a respeito da formação dos profissionais de saúde da atenção básica, segundo o entendimento de uma educação permanente em saúde tal como defendida por Emerson Elias Merhy, Laura Feuerwerker e Ricardo Ceccim, pensadores brasileiros contemporâneos. No presente texto, esta reflexão se dará a partir de dados empíricos de uma pesquisa ${ }^{1}$ com profissionais de saúde do município de Criciúma, sul do estado de Santa Catarina. A questão principal a ser debatida será: em que medida a formação em serviço ${ }^{2}$ dos profissionais de saúde da ESF possibilita sua viabilização enquanto pessoas críticas, autoras de suas práticas no seu processo de trabalho?

Primeiramente, esclareceremos alguns aspectos metodológicos da pesquisa realizada; em seguida, situaremos conceitos básicos do existencialismo sartreano, da educação libertadora freireana e da educação permanente em saúde, para, então, discutirmos a realidade vivida pelos profissionais de saúde.

\section{Orientações metodológicas da pesquisa}

A pesquisa que forneceu os dados a este artigo se desenvolveu entre agosto de 2010 e março de 2013. Foi realizada entrevista semiestruturada com enfermeiros e técnicos de enfermagem de 10 ESF do município de Criciúma. Foram escolhidas aleatoriamente $02 \mathrm{ESF}$ de cada uma das 05 Regionais de

1 Essa pesquisa, intitulada Educação Permanente em Saúde em Estratégia Saúde da Familia (ESF): uma análise sobre sua relação com o empoderamento, teve financiamento do CNPq, Edital MCT/CNPq/MEC/CAPES n ${ }^{\circ}$ 02/2010 - Ciências Humanas, Sociais e Sociais Aplicadas.

2 Nesse texto usaremos os termos "prática formativa em serviço" e "formação em serviço" para nos referirmos à educação recebida pelos profissionais de saúde. Usaremos estes termos genéricos para não confundi-los com educação continuada e educação permanente, visto serem duas formas distintas de formação, o que será ponto de análise do texto. 
Saúde do município. Ao todo, foram 09 enfermeiras (uma enfermeira não respondeu à entrevista, não se fez presente nos dois encontros marcados com este objetivo) e 17 técnicas, totalizando 26 participantes. Com o número reduzido de 10 ESF, optou-se por incluir a totalidade de enfermeiros e técnicos de enfermagem. Também foram incluídos os agentes comunitários de saúde (ACS) destas ESF, num total de 38 , mas estes dados não estão trabalhados neste artigo. Optou-se por escolher estes profissionais pelo fato de fazerem parte, obrigatoriamente, da equipe de ESF (ao contrário dos dentistas e dos técnicos de odontologia, os quais se fazem presentes apenas em algumas equipes, pois não é obrigatória a sua presença). Da equipe mínima de ESF, deixamos de contemplar os higienizadores e os médicos. Os primeiros, por entendermos que sua função não se situa na especificidade da ação de saúde, não se constituindo em uma ação fim, mas em uma ação meio para a saúde, ainda que indispensável. E os segundos por entendermos que existe uma hierarquia velada entre os profissionais da área da saúde, sendo os médicos localizados "no topo" desta pirâmide, mesmo que seja o enfermeiro o coordenador da unidade de saúde (UBS). Fizemos a opção por lançar luz aos que estão "na base", o que sugere a necessidade de outras pesquisas que problematizem a formação em serviço dos médicos.

A análise dos dados foi qualitativa, não tendo sido utilizada técnica específica de análise. Os dados foram analisados a partir do referencial teórico na busca ao alcance dos objetivos estabelecidos, os quais, neste artigo - que é um recorte da pesquisa convergem para a questão problematizada: em que medida a formação em serviço dos profissionais de saúde da ESF possibilita sua viabilização enquanto pessoas críticas, autoras de suas práticas no seu processo de trabalho?

As entrevistas foram realizadas individualmente com as enfermeiras e em grupo com as técnicas de cada UBS, em seus locais de trabalho. Em uma ESF as entrevistas foram individuais também com as técnicas, uma vez que foram realizadas a partir de um projeto de iniciação científica proveniente desse projeto maior.

As entrevistas foram gravadas, com exceção de duas, uma vez que os participantes não permitiram a gravação. Em uma ESF, a entrevista com a en- fermeira foi gravada, mas perdida. Em todos estes casos, os relatos foram imediatamente redigidos. As entrevistas foram transcritas na íntegra, e as falas foram corrigidas segundo o padrão da língua escrita. Todas as transcrições e os relatos foram devolvidos aos participantes, que fizeram as devidas correções, supressões e acréscimos, quando foi o caso, e devolveram-nas assinadas.

A pesquisa observou os preceitos da Resolução n ${ }^{\text {1 }}$ 196/96 do Conselho Nacional de Saúde, a qual redigia, na época do início de seu desenvolvimento, a pesquisa com seres humanos. Os participantes assinaram um Termo de Consentimento Livre e Esclarecido e o projeto foi aprovado pelo Comitê de Ética em Pesquisa da Universidade do Extremo Sul Catarinense (UNESC), a partir do Parecer $n^{\circ}$ 173/2011.

Para preservar a identidade das participantes, suas falas estão identificadas com as iniciais de sua categoria profissional e a ESF em que trabalham, as quais foram numeradas de 1 a 10. Assim, E-1 é a enfermeira da ESF 1. Quanto às técnicas, que foram entrevistadas em dupla, foram agrupadas com a identificação T-1, tendo ambas recebido esta identificação, por não ser relevante, nesta pesquisa, a individualização das respostas. A exceção se deu na ESF 4, em que as técnicas foram entrevistadas separadamente, recebendo a identificação T I-4 e T II-4.

\section{Liberdade existencialista, educação libertadora e educação permanente em saúde}

O pensamento de Sartre e Freire guardam proximidade na medida em que ambos situam seus pensamentos na Fenomenologia e no Materialismo histórico dialético, sendo que Sartre por vezes é citado por Freire, tendo o pensamento existencialista feito parte da constituição de sua teoria educativa. Uma vez esclarecida esta origem comum entre eles, iniciaremos com alguns pressupostos gerais da teoria sartreana, o que, em suas bases, também embasam a teoria freireana, a qual será vista em seguida.

O conceito central do existencialismo de Sartre é a liberdade. O filósofo, partindo da fenomenologia, afirma que a consciência é pura transcendência, 
é o nada, sem substância, sem estrutura, sem conteúdo, sem espaço, isto é, nem mesmo pode-se dizer que ela é vazia, pois ela é inteiramente intencional, transcendência, nada, não é um espaço, nem recipiente, é pura relação. Portanto, translúcida para si mesma, pois a única maneira de ser da consciência é ser completamente clara para si, já que seu ser se reduz ao seu aparecer. Também por isso não se pode ter um inconsciente, pois é absurdo para Sartre a consciência não ser consciente. $\mathrm{O}$ inconsciente é, inclusive, um modo de má-fé, pois ele é uma estrutura a que o sujeito não tem acesso e que o domina, e, assim, o sujeito não tem a necessidade de se responsabilizar pela sua liberdade/escolhas (MORRIS, 2009; MOUTINHO, 2001; SARTRE, 2011).

Por ser intencional (ser sempre direcionada a um objeto do qual é consciência), a consciência, nesse movimento de transcendência, faz surgir a liberdade e o engajamento como condições ontológicas do ser. A liberdade é sempre a posteriori, isto é, ela sempre é em situação. Ela é condição ontológica do ser humano, assim como o engajamento, a consciência e o próprio corpo. Juntos, são as condições para o ser se fazer sujeito, para da existência surgir a essência, isto é, um eu e o projeto de ser, que é o que sustenta o eu.

[...] o homem, antes de mais nada, existe, ou seja, o homem é, antes de mais nada, aquilo que se projeta num futuro, e que tem consciência de estar se projetando no futuro. De início, o homem é um projeto que se vive a si mesmo subjetivamente ao invés de musgo, podridão ou couve-flor; nada existe antes desse projeto; não há nenhuma inteligibilidade no céu, e o homem será apenas o que ele projetou ser. Não o que ele quis ser, pois entendemos vulgarmente o querer como uma decisão clara que, para quase todos nós, é posterior àquilo que fizemos de nós mesmos. (SARTRE, 2010, p. 26, grifo nosso).

E a liberdade é também projeto. "Não há saída, não há fuga da liberdade. Ela aparece como uma fatalidade" (WAMBIER, 2003, p. 45, grifo do autor). "Não há desculpas... não existem determinismos, o homem é livre... o homem é liberdade" (SARTRE, 1988 apud WAMBIER, 2003, p. 45, grifo do autor).

Mesmo o não escolher é uma escolha, é impossibilitada a não escolha, a todo momento se faz escolhas, sempre se vive um projeto, não ter projeto é um projeto, não se engajar é engajamento. O ser humano, para Sartre (2010), ontologicamente é liberdade, mas só é objetivamente na ação (práxis). Isto é, a pessoa só se essencializa através da relação dialética entre ela e as outras pessoas, compartilhando o mundo físico e o mundo antropológico e sociológico. Daí a afirmação de Sartre (2010) de que quando se escolhe, se escolhe para a humanidade inteira, pois o ser humano é um ser social e sociológico, então não há projeto existencial "solto" no mundo.

Quando dizemos que o homem faz a escolha por si mesmo, entendemos que cada um de nós faz essa escolha, mas, com isso, queremos dizer também que ao escolher por si, cada homem escolhe por todos os homens. Com efeito, não existe um dos nossos atos sequer que, criando o homem que queremos ser, não crie ao mesmo tempo uma imagem do homem conforme julgamos que ele deva ser. Fazer a escolha por isto ou aquilo equivale a afirmar ao mesmo tempo o valor daquilo que escolhemos, pois não podemos nunca escolher o mal; o que escolhemos é sempre o bem, e nada pode ser bom para nós sem sê-lo para todos. Se a existência, além do mais, precede a essência, e nós queremos existir ao mesmo tempo em que moldamos nossa imagem, tal imagem é válida para todos e para a nossa época inteira. Assim, nossa responsabilidade é muito maior do que poderíamos supor, pois ela envolve a humanidade como um todo. (SARTRE, 2010, p. 27, grifo nosso).

Aqui se entende que o conceito de liberdade em Sartre traz uma implicação singular, isto é, uma implicação ao indivíduo, mas também uma implicação coletiva.

Portanto, projeto de ser é uma dimensão ontológica do ser humano, sendo assim, é inerente ao homem. O homem é um ser transcendente, portanto, projeta-se no futuro. O futuro "move" o indivíduo, é o movimento de transcendência que caracteriza o homem, que só se transcende para frente, para um futuro, construindo seu projeto de ser e a história humana.

Por isto toda escolha é engajada. Se liberdade implica em responsabilidade, não há escolha que não tenha comprometimento com ela mesma. O sujeito está sempre comprometido com sua escolha, cujo valor é dado pelo fato de ter sido escolhida, é impossível não se implicar com a 
escolha, não se responsabilizar. "Tudo é gratuito. No entanto, pelo próprio fato de existir, o homem tem que sobrepujar essa gratuidade. A capacidade de ser 'bom' não é um 'dever: encontra-se na própria vida. Mas o que fazer com minha liberdade?' (GOIS, 2007, p. 12).

Partindo da análise fenomenológica do homem imerso em situação, deparamo-nos com o engajamento: esse modo humano de desvelar o mundo, encontrando-se e perdendo-se nele, de forma que por meio da necessidade de agir, a liberdade se manifesta absoluta e integralmente. Mas a liberdade do homem não é abstrata, ela implica a responsabilidade total, o compromisso e a possibilidade transformadora da realidade por meio dos nossos atos. $O$ engajamento é o desvelar feito pelo homem a partir dele mesmo: a situação adquire o sentido subjetivo que tem o próprio projeto singular, assim, o desvendar da situação provocado pelo engajamento é, ao mesmo tempo, desvendar de si mesmo. (HILGERT, 2011, p. 290, grifo nosso).

A partir dessas questões sobre a consciência, liberdade e engajamento se faz necessário falar um pouco mais sobre a questão do fenômeno e da realidade, pois a práxis está no movimento dialético do sujeito se fazer enquanto tal a partir do mundo objetivo.

E aí temos a dialética do objetivo e do subjetivo, que é a necessidade da interiorização do exterior e da exteriorização do interior. Para ele [o indivíduo], a práxis é esta passagem do objetivo ao objetivo pela interiorização. O projeto é uma superação subjetiva da objetividade em direção a objetividade; uma tensão entre condições objetivas do meio e as estruturas objetivas do campo de possíveis; a unidade da subjetividade e da objetividade (SARTRE, 1979 apud WAMBIER, 2003, p. 48, grifo nosso).

Isso quer dizer que vivenciamos o universal como singular, e também o singular como universal. A liberdade está sempre situada nas condições concretas da existência.

Para Sartre, de acordo com Wambier (2003), o papel histórico do existencialismo é o de afirmar e recolocar na discussão filosófica a singularidade humana, a realidade humana, o saber, a universalidade dos conceitos, mas não como Hegel (espírito objetivo, como entidade separada do ser humano concreto), e sim na totalidade ou universalidade pensada por Marx, como um processo aberto e sempre em porvir.

Penso que o que Sartre nos convida a pensar é justamente isto: a liberdade não é uma ideia, mas uma realidade concreta que se efetiva através da práxis coletiva ou de um projeto coletivo. Mas, a práxis coletiva depende da práxis individual, ou seja, do engajamento. Para que haja práxis individual, o indivíduo precisa querer, desejar, trabalhar e agir. Ele precisa ter paixão pelo homem e pela humanidade. A lição que tiramos de Sartre para os nossos dias é a seguinte: ou escolhemos o quietismo e a indiferença perante as questões levantadas acima ou escolhemos um novo projeto de ser de sociedade, dentro de um campo de possíveis e passamos a dar um sentido para nossas vidas: fazendo história. A contemporaneidade do pensamento de Jean Paul Sartre reside em seu caráter anti-niilista. Para ele, apesar de tudo, é preciso continuar e para continuar a liberdade é fundamental. (WAMBIER, 2003, p. 53, grifo do autor).

Podemos afirmar que a teoria educativa freireana parte dessa mesma base e do mesmo intento de engajamento no mundo.

Quando falamos da educação ou pedagogia libertadora, estamos compreendendo que existe uma possibilidade de transformação que ela é capaz de produzir nas pessoas, na sua forma de agir e repensar a sociedade como um todo, pois faz delas, oprimidas pelo atual sistema capitalista em que estamos embrenhados, atuantes no sentido de transformar a realidade objetiva.

Paulo Freire (2005), em sua Pedagogia do Oprimido, traz uma concepção de educação que traduz o conflito existente na sociedade de sua época, e que se perpetua na atualidade, a qual ele denomina de "educação bancária". Essa concepção diz respeito à falta de comunicação existente entre os principais interlocutores da educação, os educandos e os educadores.

Com o ato de "depositar" conteúdos resume-se o conceito de educação bancária, pois nele o educando é um mero depositário de conteúdos e o educador é o que deposita todos os conhecimentos da maneira que ele pensa ser a correta. E onde ficam os conhecimentos e as reflexões dos educandos? Eles não são, também, autores da história? Para a educação bancária não, pois ela vê o mundo de 
forma determinista, dada, não dialética, o que favorece a sociedade opressora manter o status quo, neutralizando as ações que possam surgir para sua transformação, o que se supõe vir dos oprimidos. Os oprimidos, para Freire (2005), são todos aqueles a quem é negada sua condição ontológica de "ser mais", situados em uma sociedade estruturalmente injusta.

A liberdade em Freire é a realização da vocação ontológica do homem, que é o 'ser mais', entendido como transcender-se. O 'ser mais' é realizado em comunhão com outros homens, pelo diálogo, que possibilita a conscientização. Esta se dá a partir da consciência transitiva crítica - conceito que equivale ao de consciência reflexiva crítica de Sartre -, que possibilita a libertação, a emersão do homem da situação que o 'engolia', e na qual se via como passivo. (MOREIRA; ROSA, 2014, p. 420).

Assim, "a consciência e a liberdade em Sartre são do domínio ontológico, pois são constitutivos do ser do homem. Em Freire, a consciência também é ontológica, porém, a liberdade é decorrente, em termos antropológicos, do 'ser mais', este sim, ontológico". (MOREIRA; ROSA, 2014, p. 421). Se para Sartre o que é da condição ontológica do homem é a liberdade, para Freire esta condição é o "ser mais", mas tanto uma como a outra têm o sentido de inacabamento e indeterminação do homem. A liberdade em Freire é a liberdade de "ser mais", condição negada em contextos de opressão, porém, que jamais desaparece, uma vez se dar no nível ontológico.

Para Paulo Freire (2005, p. 79), “[...] ninguém educa ninguém, como tampouco ninguém se educa a si mesmo: os homens se educam em comunhão, mediatizados pelo mundo", o que deixa clara sua visão materialista histórica, uma vez que o mundo é uma objetividade que mediatiza a ação humana. E também deixa clara sua concepção educativa, pautada na dialogicidade, na comunicação entre as pessoas, não na imposição da verdade de uns sobre os demais. Esta comunhão em Freire está relacionada ao contexto, e o resultado desta comunhão seria a autonomia do sujeito, não no sentido liberal autocentrado, mas de inserção crítica no contexto social, em meio a outros homens.

Essa concepção descreve o respeito que deve existir nas relações entre educador e educando. Os educandos não são mais fiéis depositários, e sim construtores dessa nova realidade. São chamados a construir o conhecimento e não mais a memorizar o conteúdo.

Os educandos começam a mudar sua consciência ingênua para a consciência crítica da realidade em que vivem. E isso por se sentirem desafiados a desvelar o mundo, tornando o homem inserido no mundo, e não mais alheio a ele.

Pelo fato mesmo de esta prática educativa constituir-se em uma situação gnosiológica, o papel do educador problematizador é proporcionar, com os educandos, as condições em que se dê a superação do conhecimento no nível da doxa pelo verdadeiro conhecimento, o que se dá no nível do logos. Assim é que, enquanto a prática bancária, como enfatizamos, implica uma espécie de anestesia, inibindo o poder criador dos educandos, a educação problematizadora, de caráter autenticamente reflexivo, implica um constante ato de desvelamento da realidade. A primeira pretende manter a imersão; a segunda, pelo contrário, busca emersão das consciências, de que resulte sua inserção crítica na realidade. (FREIRE, 2005, p. 80, grifo do autor).

$\mathrm{O}$ que o autor entende por consciência ingênua seria aquela que não questiona as verdades estabelecidas, e nem se insere criticamente na realidade. Todavia, a partir da ação do educador, o qual promove o diálogo, esta consciência ingênua passaria para uma consciência crítica, desveladora do mundo em que se está inserido, caracterizando a educação conscientizadora ou libertadora. Para Freire (2005), como vimos, a vocação ontológica do homem é "ser mais", o que implica em viver em condições que permitam sua humanização, sua politização, seu pensamento crítico e a autonomia em suas escolhas.

Tendo no horizonte a noção de liberdade e de engajamento, é em direção à distinção entre educação bancária e educação permanente que se pode compreender a educação continuada e a educação permanente em saúde, aqui pensada no contexto da saúde pública.

Colocando em foco a política pública de saúde, Ceccim e Feuerwerker (2004) defendem o que chamam de quadrilátero da formação para a área da saúde, formado pelo ensino (instituições de ensino), gestão (gestores da saúde pública), atenção (profis- 
sionais da saúde) e controle social (usuários). Os autores entendem que a formação de profissionais não implica apenas em habilidades técnicas e de pensamento, mas também em adequado conhecimento do SUS e em produção de subjetividade:

A formação não pode tomar como referência apenas a busca eficiente de evidências ao diagnóstico, cuidado, tratamento, prognóstico, etiologia e profilaxia das doenças e agravos. Deve buscar desenvolver condições de atendimento às necessidades de saúde das pessoas e das populações, da gestão setorial e do controle social em saúde, redimensionando o desenvolvimento da autonomia das pessoas até a condição de influência na formulação de políticas do cuidado. (CECCIM; FEUERWERKER, 2004, p. 43).

Note-se que os autores fazem referência a uma formação profissional que promova a autonomia da população. Para que os profissionais possam relacionar-se com usuários que vivenciam sua autonomia e também possam promover esta autonomia nos usuários, no entanto, é preciso eles mesmos vivenciá-la ou, quando não, terem o desejo e a atitude de construí-la.

Os autores citados defendem que o setor ensino, de formação do profissional, expresse os interesses públicos. Eles defendem que além do ensinamento das questões técnicas, deve-se também disseminar "os saberes produzidos nos serviços, nos movimentos sociais e nas práticas populares" (CECCIM; FEUERWERKER, 2004, p. 44), condição importante para a construção da autonomia acima referida.

Para os autores, a educação permanente em saúde deve ser estruturada a partir da problematização dos profissionais de saúde de seu processo de trabalho. "Seu objetivo deve ser a transformação das práticas profissionais e da própria organização do trabalho, tomando como referência as necessidades de saúde das pessoas e das populações, da gestão setorial e do controle social em saúde" (CECCIM; FEUERWERKER, 2004, p. 49).

A Política Nacional de Educação Permanente em Saúde (PNEPS) do Brasil foi direcionada por esta proposta, ainda que tenha sofrido modificações ao longo do tempo. Na Portaria $n^{\circ} 1996$, de 20 de agosto de 2007, em seu Anexo II, assim é definida a EPS:
A Educação Permanente é aprendizagem no trabalho, onde o aprender e o ensinar se incorporam ao cotidiano das organizações e ao trabalho. A educação permanente se baseia na aprendizagem significativa e na possibilidade de transformar as práticas profissionais. A educação permanente pode ser entendida como aprendizagem-trabalho, ou seja, ela acontece no cotidiano das pessoas e das organizações. Ela é feita a partir dos problemas enfrentados na realidade e leva em consideração os conhecimentos e as experiências que as pessoas já têm. Propõe que os processos de educação dos trabalhadores da saúde se façam a partir da problematização do processo de trabalho, e considera que as necessidades de formação e desenvolvimento dos trabalhadores sejam pautadas pelas necessidades de saúde das pessoas e populações. Os processos de educação permanente em saúde têm como objetivos a transformação das práticas profissionais e da própria organização do trabalho. (BRASIL, 2007).

A Portaria $n^{\circ} 278$, de 27 de fevereiro de 2014, segue a mesma lógica conceitual. Em seu Artigo $2^{\circ}$, Inciso I, assim está definida Educação Permanente em Saúde: "aprendizagem no trabalho, onde o aprender e o ensinar se incorporam ao cotidiano das organizações e ao trabalho, baseando-se na aprendizagem significativa e na possibilidade de transformar as práticas dos trabalhadores da saúde" (BRASIL, 2014a). O mesmo documento define como aprendizagem significativa em seu Artigo $2^{\circ}$, Inciso II: "processo de aprendizagem que propicia a construção de conhecimentos a partir dos saberes prévios dos sujeitos articulados aos problemas vivenciados no trabalho" (BRASIL, 2014a).

Buscando as bases da EPS, Merhy, Feuerwerker e Ceccim (2006) dizem que a condição para que uma pessoa deseje mudar aquilo que faz e vive é um sentimento de incômodo com a situação atual, constatado o fato de que, dispondo dos recursos que já possui, ou continuando a fazer o que já faz, a situação não irá mudar. E isto, numa situação educativa, só poderá ocorrer mediante a reflexão das vivências e práticas do cotidiano. Este também seria o princípio da educação de adultos: refletir sobre o vivido para constatar a necessidade da mudança e desejar construir esta mudança.

Uma informação ou experiência pedagógica somente produz sentido quando dialoga com toda a acumulação anterior que as pessoas trazem consigo. 
Partir dos incômodos, dialogar com o acumulado e produzir sentido, são as chaves para a aprendizagem significativa. O processo de trabalho em saúde é tomado, então, como objeto de reflexão com a participação ativa dos trabalhadores de saúde. Os processos educativos se constroem a partir da realidade dos trabalhadores, de suas concepções e de suas relações de trabalho. (MERHY; FEUERWERKER; CECCIM, 2006, p. 153, tradução nossa).

Ao lado da reflexão do cotidiano, os autores atribuem importância à análise institucional e às pedagogias institucionais, as quais levarão ao conhecimento das relações sociais estabelecidas no ambiente de trabalho, o que permitirá relacionar o nível macrossocial com o microssocial. Segundo os autores, esta é uma condição para que os profissionais de saúde sejam autores de seus atos. Esta proposta coincide com a visão de Freire e Sartre de que a atitude singular só ganha sentido se compreendida em seu contexto. "Uma das finalidades da EPS, portanto, seria a contribuição para que cada coletivo pudesse conquistar a capacidade de ser seu próprio coautor em meio de um processo de reinvenção das instituições de saúde" (MERHY; FEUERWERKER; CECCIM, 2006, p. 154, tradução nossa).

Uma questão importante a se pontuar nessa reflexão sobre o processo educativo em saúde é a caracterização do próprio processo de trabalho em saúde. Merhy, Feuerwerker e Ceccim (2006) destacam que uma das especificidades do trabalho em saúde é sua consolidação "em ato", ou seja, é durante o trabalho entre profissional e usuário que a saúde é produzida. Isto traz uma possiblidade de autonomia aos profissionais de saúde, os quais são regidos pelas normatizações do sistema por um lado, mas de outro têm a condição de desempenhar sua função no mesmo ato em que a produzem.

Nesse ato, deve-se compreender que existe a possibilidade de ocorrerem três níveis de emprego de tecnologia em saúde: as tecnologias "duras", que correspondem aos equipamentos necessários à realização de exames e procedimentos, e também aos medicamentos; as "brandas-duras", que correspondem aos conhecimentos estruturados, como a clínica e a epidemiologia; e as "brandas", que correspondem ao relacionamento do profissional com o usuário, o que envolve toda a relação que estas pessoas podem estabelecer no processo de trabalho em saúde (MERHY, 1997 apud MERHY; FEUERWERKER; CECCIM, 2006). São as tecnologias brandas que conferem vida ao trabalho em saúde, uma vez que permitem ao profissional buscar conhecer a situação concreta de vida dos usuários, o que direciona à criatividade (MERHY, 2002 apud MERHY; FEUERWERKER; CECCIM, 2006). Para os autores, é daí que advém a autonomia e a possibilidade de o trabalho produzir sentido para o profissional e, melhor seria, também ao usuário. E é este fator que confere a condição de que o trabalho em saúde não é totalmente controlável, já que está baseado nas relações estabelecidas entre as pessoas. Como diz Sartre (2010, 2011), pessoas são liberdades. E é o cotidiano, o "micropolítico", o lugar que possibilita ao profissional ouvir dos usuários as suas necessidades, assim como compreender suas demandas em seu contexto.

A partir desses fundamentos, a educação permanente em saúde se diferencia da chamada educação continuada em saúde, pois esta se caracteriza como pontual e fragmentada; ter por finalidade a atualização de conhecimentos específicos; o enfoque se situar na transmissão do conhecimento a ser atualizado; sua planificação ser descendente - a partir de uma visão geral dos problemas, o que gera cursos que são ministrados como solução para estes problemas; seu planejamento ser centralizado, não local, e seguir uma padronização; a ênfase se dar no aspecto cognitivo (MERHY; FEUERWERKER; CECCIM, 2006).

Podemos afirmar que a educação continuada é realizada segundo a educação bancária, e a educação permanente segundo a educação libertadora.

Essa distinção fica evidenciada pelo Ministério da Saúde ao definir educação permanente em saúde em contraposição à educação continuada, inclusive citando o referencial freireano:

Nosso desafio é superar um histórico de atendimento apenas aos processos de educação continuada dos trabalhadores do MS com base nas demandas individuais de capacitação, em detrimento de ações de Educação Permanente em Saúde. Sendo assim, a aposta é fortalecer a Educação Permanente (EP) como norteadora de novas práticas que orientam a reflexão sobre o trabalho e a construção de processos de aprendizagem colaborativa e significativa, ofer- 
tando ações coletivas de desenvolvimento aos trabalhadores, a partir dos principais desafios identificados pelas equipes no cotidiano do trabalho. Afinal, como nos ensina Paulo Freire (1989), o ser humano não pode ser compreendido fora de seu contexto. Ele é o sujeito de sua própria formação e se desenvolve por meio da reflexão sobre seu lugar no mundo, sua realidade e suas vivências. (BRASIL, 2014b, p. 5).

Assim,

Para apoiar a construção de conhecimentos, habilidades e atitudes, as ações educativas devem ser compreendidas para além do sentido clássico da aquisição de conhecimentos técnico-científicos referidos a uma dada profissão e aplicados a uma dada realidade, como um processo de produção de sujeitos críticos e reflexivos, transformação da realidade, constituição de modos de existência e criação de novas formas de gestão dos processos de trabalho. (BRASIL, 2014b, p. 7).

Nosso convite é que a proposta de EPS fundamentada em Merhy, Feuerwerker e Ceccim (2006) se concretize na Política Nacional de Educação Permanente em Saúde (PNEPS), por configurar-se, segundo nosso olhar, a partir da educação libertadora e também do engajamento da liberdade existencialista. Neste sentido pode-se entender esta síntese sobre a EPS: "o mundo do trabalho, nos encontros que provoca, se abre para nossas vontades e desejos, nos condenando também à liberdade e a nos enfrentarmos com nós mesmos, com nossos atos e com nossas implicações" (MERHY, 2005 apud MERHY; FEUERWERKER; CECCIM, 2006, p. 159, tradução nossa).

Sigamos, agora, às vivências de formação em serviço dos profissionais de saúde.

\section{Formação em serviço dos profissionais de saúde}

As profissionais entrevistadas - todas mulheres apresentam tempo de formadas e de trabalho bastante variado, indo de poucos meses à proximidade de 20 anos, variando também suas idades cronológicas. Todas as respostas foram consideradas a partir de sua expressão qualitativa, sem se fazer o cruzamento destas variáveis. Foi almejado compreender os sentimentos expressos em relação à formação em serviço, o que levou à problematização das condições de trabalho. Isto se deu de forma generalizada, a partir do entendimento de que estas expressões compõem a situação concreta, não se problematizando seus matizes individuais. Igualmente, não se problematizou a questão de gênero nesta pesquisa. Estas derivações poderão ser objeto de futuras análises.

A maioria das 10 equipes de ESF pesquisadas apresentava número de ACS inferior ao necessário, o que acarretava em microáreas descobertas. Uma delas apresentava apenas uma técnica em enfermagem - quando o preconizado são duas -, e uma ESF estava sem nenhuma técnica. Também se destaca a grande rotatividade de profissionais nas ESF.

Em termos de formação em serviço, as entrevistas focaram aspectos da formação recebida em forma de cursos, as chamadas capacitações, promovidas pela Secretaria de Saúde e, no caso estudado, tendo grande parceira com a universidade local. Foram questionados o formato destas capacitações e a maneira como as profissionais as perceberam. Para contextualizar estas respostas, foram questionados também aspectos do cotidiano do trabalho, assim como suas dificuldades e suas satisfações.

Considerando as duas categorias profissionais, houve referência a vários cursos realizados, alguns específicos para cada categoria, outros para enfermeiras juntamente com as técnicas, alguns para toda a equipe. A duração foi variada, tendo havido um curso de dois anos, de periodicidade semanal, com toda a equipe, realizado na universidade, sobre aspectos gerais da ESF; também houve cursos menores, de um ano, de meses, de semanas, de dias e de apenas um dia. A análise aqui realizada é generalizada, não é específica por curso. Isto não significa que estas variações não sejam portadoras de diferentes possibilidades de criticidade dos profissionais envolvidos. Um curso de média e de longa duração teria a possibilidade de promover maior criticidade em todo seu processo. Ou não. Isto irá depender do seu objetivo, de sua orientação. Parte-se do entendimento de que uma educação libertadora, enquanto opção, pode estar presente em qualquer curso, de qualquer duração e de qualquer assunto. Não é o tema e a duração que possibilitam uma formação crítica, mas seus propósitos. Isto não retira a importância de se levar em conta estas variações. Contudo, este não foi o propósito desta pesquisa. 
Os assuntos são, em geral, específicos: direcionados aos períodos de campanha de vacinação e gripe A, doenças sexualmente transmissíveis (DST) e AIDS, drogadição, hepatite, injetáveis, curativos, tuberculose, primeiros socorros, preventivo, coleta cito-patológica, vigilância nutricional e alimentar, lavagem de materiais (procedimentos), atenção à gestante e puerpério, humanização, saúde do trabalhador, saúde mental, autoestima etc. Muitos dos conteúdos são sugestões das próprias profissionais ao final de um curso, quando se lhes é perguntado quais temas gostariam que fossem abordados nos próximos. Eles também são sugeridos nas reuniões mensais das coordenadoras de Unidade Básica de Saúde (UBS) com a Coordenação da Atenção Básica da Secretaria de Saúde. Alguns assuntos são oferecidos todos os anos, como tuberculose, hepatite e hanseníase.

Segundo as falas das profissionais, a metodologia dos cursos, em geral, inicia com a exposição do conteúdo, abre-se para a discussão e, dependendo do assunto, faz-se a prática, muitas vezes nos laboratórios da universidade, o que foi bastante valorizado. As dinâmicas também têm sua importância reconhecida, sentidas como um espaço de liberdade, de valorização por poderem expressar seus sentimentos; outro ponto positivo das dinâmicas é o fato de o curso não ser apenas teórico, o que é considerado cansativo. Houve a fala de uma enfermeira apontando que prefere quando é teoria e prática e não "teatrinho", dando a entender que seu estilo pessoal é reservado, não gostando de expor-se. Também há trabalhos que devem ser feitos fora da aula e apresentados em equipe.

A partir dos dados encontrados, quando faltam ACS em uma UBS o trabalho específico de visitas às casas não é realizado. Quando necessário, é feita a visita específica dos outros profissionais, mas a UBS fica sem os dados necessários para caracterizar o perfil epidemiológico da região e sem saber das necessidades da população que não a frequenta.

Uma situação ímpar é a das enfermeiras, as quais possuem dupla função na UBS: a de assistência e a de gerenciamento, muitas vezes chamado de burocrático. Esta é uma divisão difícil de equilibrar, pois ao mesmo tempo em que a população demanda assistência, cresce a demanda da gestão municipal (a qual também é cobrada pela gestão estadual e federal) por envio de dados, relatórios, metas a cumprir (de atendimento e vacinação), controle de medicação. As técnicas também fizeram referência a estes controles. A situação específica das enfermeiras se dá pela sua situação de coordenadoras da unidade, às vezes chamadas de gerentes. Todavia é geral a sensação de exaustão devido ao volume de trabalho a realizar, muito registro, muito papel.

Mas se a gente quer coisas novas, coisas para a gente poder trabalhar, tem de ser coisas que a gente tem, não é papel, papel, papel. A gente quer coisas práticas. Vai, faça, e que deixe o cliente satisfeito. $E$ que sabe que hoje a gente tá bem, assim, triste que é muito papel, então, assim, tem mais papel aqui do que gente para atender, vamos dizer assim. (T-2).

Esse "excesso de papel" acarreta em um sentimento de não realizar seu trabalho assistencial de acordo com a necessidade do usuário, assim como em levar trabalho para casa.

Para tu teres uma noção, sou uma vacinadora, então tu colocas um curativo, fazes uma vacina, vais lá e fazes um preventivo, e é tudo corrido, tudo corrido, um quer falar, outro quer falar, só que aquilo ali tu tens que fazer no final do mês essas coisas e eu não consigo fechar o meu relatório da vacina aqui, eu tenho que levar para casa, eu levo quatro horas para fechar. [...] então, se eu deixar de contar uma gota vai ter um furo lá na frente, então, assim, eu acho que hoje é muito papel. (T-2).

Não é essa a percepção desta técnica, perguntada se a necessidade de preencher relatórios não dificultava o trabalho assistencial:

Eu acho que não tanto. Porque a gente procura, eu faço o preventivo, faço a vacina, ela faz a parte burocrática. Claro que às vezes sobrecarrega, a enfermeira é sobrecarregada de trabalhos, mas muitas vezes a gente deixa de fazer um trabalho porque tem o que fazer, relatório, essas coisas. Mas a gente procura assim ó, fazer da melhor maneira possivel, se não dá hoje, dá amanhã. [...] eu estou muito contente com a nossa equipe. (T-7).

Entretanto, a exaustão também se deve à equipe incompleta.

Eu ia para casa cansada e não dormia, e ficava pensando assim: 'Meu Deus! Amanhã vai ser outro dia! Será que eu vou conseguir? 'Sabe? 


\section{$[\cdots]$}

Eu sei que eu estou me prejudicando, tá? A minha saúde está assim, no limite, meu estresse está no limite, está tudo no limite, eu sei que não está fazendo bem para mim. Mas amanhã é outro dia. (E-1).

Em outra situação, a equipe incompleta não é vivenciada como problema:

Às vezes tem uma ficha para fazer de um agente comunitário, a área está descoberta, então nós não vamos abrir uma fichinha, um prontuário para aquela paciente porque a área está descoberta? Não existe isso! Já faz três anos que está descoberta, então o paciente nunca vai ser atendido por aqui? O que a gente faz? Vai lá e faz o papel do agente comunitário. E faz o nosso papel, e a gente ficou oito meses sem ninguém para limpar a unidade, nós limpávamos banheiro, varríamos aqui e lá fora. Então, eu acho que isso tudo é muito da equipe, porque nós temos uma equipe boa, entendeste? (T-10).

Também se averiguou a dificuldade em se ausentar da UBS para os cursos, pois o trabalho "fica esperando", o que acarreta em precisar levar trabalho para casa, principalmente quando as equipes estão incompletas.

Prevalece a compreensão de que os cursos são lugares de atualização de conteúdos e práticas, pelo fato de "as coisas mudarem muito rápido" e há que se atualizar para não fazer procedimentos já superados, ou mesmo para relembrar assuntos esquecidos por não serem muito usados no dia a dia, ou aprender o que não se aprendeu na formação inicial. Os cursos permitem mudar os hábitos, porque o trabalho é mecânico, rotineiro, precisa-se ter momentos para refletir, atualizar-se. Há a sensação de que os cursos proporcionam segurança ao profissional em seus atendimentos. Também foi dito que, na correria do dia a dia, precisa-se ter espaço e tempo fora de seu local para poderem estudar. Contudo também foi apontado o caráter "desestressor" dos cursos, por proporcionarem saírem da rotina, irem a outros lugares, falarem com outras pessoas, trocarem informações, verem que outros profissionais enfrentam os mesmos problemas.

As percepções quanto ao formato dos cursos se dividem. Uma enfermeira aponta a necessidade de cursos que separem e que integrem os profissionais da equipe, dependendo da temática, pois não adianta integrar todos quando o assunto for muito específico de uma função.

Outras preferem cursos com toda a equipe. Falou-se de um sentimento de valorização e de liberdade quando todos estão juntos, o que é entendido como "sem discriminação", não sendo separados por "méritos" ou "questão de diploma de nivel superior" (T-3). A técnica sugere que sejam realizados encontros com toda a equipe, com todas as equipes de uma mesma Regional de Saúde, mensalmente.

Também esteve presente na fala de duas técnicas da mesma ESF a defesa de estarem todos juntos porque o médico ajuda na realização das tarefas de grupo, e também porque ele pode defender as ideias da equipe. Constata-se a centralidade da figura do médico na vivência das profissionais, entendido como aquele que possui mais conhecimento e mais poder para se expressar. Esta noção está presente no imaginário de profissionais e de usuários, e se deve ao modelo biologicista médico centrado da saúde, mesmo que o SUS preconize um modelo multiprofissional. A própria ESF, que também traz um modelo multiprofissional, pode já avançar no sentido de ampliar sua equipe mínima para outros profissionais.

Nós tínhamos liberdade naquela época que era tudo junto, os profissionais, não importava, era médico, enfermeiro, tudo junto, e tinha momento que os médicos nos ajudavam a defender o que a gente precisava, né? Eles tinham essa liberdade, nós nos sentíamos bem melhor. (T-3).

Não eram coisas divididas... não era assim, hoje é só para técnico, hoje, não, tudo junto. Até na hora de participar, de fazer algum texto, era bem melhor, porque tinha a participação de todo mundo para te ajudar. Porque se eu não sei, essa tem uma ideia, aquela lá tem uma ideia, já ajudava, é bem mais prático. (T-3).

Uma enfermeira aponta que o enfermeiro tem mania de reclamar do médico, assim como ela tinha. Depois começou a pensar que o enfermeiro ainda não conseguiu demonstrar que é tão importante quanto ele.

Se ele [médico] tem espaço, se ele é tão importante, se a medicina curativa ainda perdura, é porque nós, enquanto profissionais de saúde, enquanto enfer- 
meiros, não conseguimos, ainda, atingir o nosso objetivo, que é fazer as pessoas verem o quanto o profissional enfermeiro é importante dentro da saúde pública, tanto quanto o médico, não mais, eu diria, porque ninguém é mais que o outro. Mas tanto quanto o médico. (E-10).

Houve um curso muito comentado, sobre a ESF, realizado na universidade, com todas as equipes e com todos os profissionais das equipes. Esta experiência foi valorizada pelo aspecto de saírem da UBS uma tarde por semana, sendo um "desestressor": ir a outro lugar, ver outras coisas, falar com outras pessoas. Também fizeram referência à presença de massoterapeuta e psicóloga nos cursos, e à possibilidade de poderem ouvir coisas que lhes tocavam e de fazerem relaxamento.

E tem uma coisa que eu penso, assim, que nós, muitas vezes, somos esquecidos, de como o usuário também, né, porque a gente cuida, tenta auxiliar o usuário lá fora com relação à prevenção da saúde dele, e a fornecer a medicação para ele, mas nós, muitas vezes, aqui dentro, também estamos adoecidas. Pode até ser que a gente não transpareça, mas todo mundo tem uma queixa, um dia uma dor na perna de tanto andar nesse corredor para lá e para cá, e vai à rua, faz isso, faz aquilo outro. [...] E tratar também da nossa saúde, essa questão de sair do ambiente de trabalho, relaxar, é importante porque a gente vai lá, recebe uma massagem, que tinha massoterapeuta que fazia, um psicólogo que abordava um determinado assunto, que muitas vezes tocava, que parecia que estava falando para ti e lá tu choravas ou tu rias, ou tu te prostravas mais, é bom. Também temos que ser tratadas, porque para ajudar a tratar dos outros tem que estar bem. Então eu achava muito importante. (T-3).

Essas técnicas sentiam-se protegidas, acolhidas, amparadas. Defendem que volte a ser assim: palestras, descanso, lanche, conversa, dinâmica. Elas falavam, trocavam umas com as outras suas vivências. Agora, com os cursos separados por categoria profissional, são mais conteúdos técnicos. O médico ajudava a defender o que precisava. E podemos questionar: será que se sentiam mais amparadas pela presença do médico? Ele as respaldava quando falavam? Ele falava por elas? O sentimento de acolhimento se deve pela presença dos "superiores"? Pela acolhida de todo o curso?
Pelo desabafo? Será que existe um sentimento de discriminação com a separação dos cursos por categorias de profissionais? Será que se sentem menos capazes de relatar, escrever e precisam que os "mais estudados" façam por elas? Estas são questões que permeiam o cotidiano dos serviços, e que deveriam ser foco da EPS.

Assim como na fala anterior, em várias outras situações foi apontado o adoecimento que sofrem por conta das pressões do trabalho, seja por seu excesso, seja por serem maltratadas pelos usuários, seja por vivenciarem medo em seus locais de trabalho, principalmente em UBS situadas em bairros reconhecidos como violentos. Principalmente nestes, houve a solicitação explícita de que a Secretaria de Saúde faça um trabalho de saúde mental com as profissionais, para suportarem a pressão. $\mathrm{O}$ entendimento é de que quem cuida dos outros precisa ser cuidado. Uma técnica foi explícita: "Eu estou precisando de ajuda". E continua:

Eu acho, hoje, que tinha que fazer, sei lá, alguém de fora tinha que fazer alguma coisa, para ver como estão os funcionários da Prefeitura, porque hoje não somos apenas nós, acho que são todos, principalmente os bairros que têm mais carência, porque eles vêm em busca de alguma coisa, se eles não levam uma coisa, a culpada vai ser tu, então, assim, aquilo ali vai te machucando. Eu digo sempre para as meninas, [...] eu sou uma pessoa que está toda vida sorrindo, brincando com os pacientes, eu não tenho mais isso, pode ver o semblante de cansaço. E eu não tenho mais isso, e eu peguei férias em dezembro [a entrevista foi realizada no mês de março do ano seguinte]. (T-2).

A necessidade de se ter um espaço para que as profissionais sejam ouvidas foi amplamente manifestada. E este espaço poderia ser a partir de um trabalho com psicólogos nos seus próprios locais de trabalho, ou nas reuniões mensais com a Secretaria de Saúde, ou nas capacitações:

[...] eu tenho uma técnica que está comigo há três anos, ela é ótima, mas tem dia que eu tenho que dar folga para ela porque ela está só chorando. Isso acontece comigo também, mas eu sou um pouco mais forte porque tenho um controle psiquiátrico do lado, com a minha médica. Então, será que não precisa trabalhar essa questão 'pessoa'? Olhar para a pessoa e não para o servidor e funcionário, cola- 
borador, sei lá como se chama isso. Vários nomes que, para mim, é uma coisa só: pessoa, né? Então eu acho que isso, o olhar clínico, com relação a isso tem que ter $[\ldots]$ (E-9).

Algumas dificuldades são apontadas no cotidiano de seu trabalho e ganha destaque a falta de materiais - incluindo luvas de proteção, como também materiais de manipulação direta com os usuários - e medicamentos na UBS. Também falta de materiais para se fazer prevenção, o que leva a um desgaste no profissional, que precisa ir atrás disto. Algumas vezes no próprio curso se fornece o material, o qual é guardado na UBS para ser utilizado. Muito referidos a maus tratos dos usuários, a maioria das vezes justamente por estas faltas e pela demora no agendamento de consultas. Nenhuma destas questões depende delas, no entanto, são elas que ouvem as manifestações de descontentamento. Também o próprio fato de não se conseguir resolver uma demanda urgente de algum usuário é, em si, visto como uma dificuldade, ainda que também acompanhe a cobrança do usuário.

Muita coisa, às vezes, tipo assim, tu vais explicar para o paciente que uma consulta ou um agendamento está demorando, é complicado! Que a gente se coloca no lugar dele, a gente vê, assim, que demora e ele está precisando, o que a gente vai fazer se não depende da gente?! No fim, tu acabas, tipo assim, tem que explicar todo dia, todo dia, não pra um só paciente, mas pra vários que não tem, que está demorado. Isso acaba gerando um desgaste mental pra gente. Então, como é que tu vais trabalhar bem se vem um monte de gente te pressionar: 'Ah não tá saindo... isso, isso e aquilo”. É bem complicado. (T I-4).

Algumas satisfações também são apontadas, e ganha destaque sua valorização por parte dos usuários, os quais ficam agradecidos por seus esforços em atendê-los: “[...] alegria é quando eles vêm felizes porque conseguiram, vêm com um muito obrigado. A gratidão né... gratidão deixa a gente feliz, eu acho isso, né? Quando eles dizem muito obrigado né, a educação das pessoas". (T-7).

Também é apontado como satisfação no trabalho o bom relacionamento na equipe, a parceria que encontram nos colegas.

Partindo da especificidade do trabalho da enfermeira na UBS, de assistência e de gestão, todas as enfermeiras apontaram-na como uma forma de tensão, pois desejam priorizar a assistência, mas não conseguem devido à cobrança por fornecimento de dados. Quando conseguem priorizar a assistência, fica a vivência da cobrança. No entanto, segundo uma enfermeira, a maior parte das capacitações é direcionada à assistência. Isto não foi apontado por ela como uma crítica. Todavia podemos pensar que se a EPS objetiva problematizar o vivenciado em serviço, e se as demandas da gestão tomam a maior parte do tempo das enfermeiras, este tema deveria ter lugar nos espaços de formação. Claro que, mesmo tendo como tema um assunto vinculado à assistência, as dificuldades vivenciadas nesta assistência devido ao tempo dividido com a gestão poderiam - e deveriam - ser abordadas, afinal, são partes distintas de uma mesma totalidade.

Diante de todo esse contexto em que estão inseridas suas vivências cotidianas de trabalho, há espaços nas capacitações oferecidas para se falar sobre isto? Aqui há posições diferenciadas: algumas afirmam que sim, há momentos de discussão em que as participantes trocam suas experiências e assim podem aprender umas com as outras e, inclusive, discutir as angústias de seu trabalho. No entanto, na maioria das vezes esta troca significa dizer se na sua UBS é viável ou não realizar determinado procedimento ensinado, segundo a explicação de que nem tudo o que é ensinado na teoria é viável na prática, e nos cursos há lugar para se dizer isto.

Nossas educações nunca é filinha e uma na frente. É sempre um círculo e a gente debatendo: 'Ah, na minha Unidade não dá para fazer isto, na minha Unidade não dá pra fazer aquilo'. Ou a gente também: 'Eu estou fazendo isto e está dando certo'. E a gente pega a ideia e começa a colocar aqui. (E-2).

Infelizmente é, eu acho que a população fica mais de lado e o papel fica mais na frente. [...] e assim, esse curso do financeiro está falando só de papel, de papel para nós preenchermos, de notificação para fazer, dai eu virei para a menina que estava do lado, eu disse assim ó: 'Preciso de uma secretária', que chatice, tanto papel, tanto papel, é notificação daqui $e$ é notificação dali, e até agora de atendimento ao paciente não falou. Dai eu perguntei para a moça, eu falei: 'Escuta, você não acha papel demais?' 'Ah, mas é obrigatório, porque é relatório, porque não sei o que, não sei o que'. Eu assim, ó: 'Lá na Unidade, 
nós atendemos quatro bairros'. Nós somos uma unidade que atende quatro bairros. (T-2).

Também há situações de debate, em que se problematiza as condições concretas do trabalho:

Foi bem interessante, porque, assim, elas falavam, depois elas faziam uma prática, então, assim, depois tinha dúvida, a gente perguntava: 'Ah, mas lá no nosso posto a gente não faz assim, não, mas pode fazer'. Não, mas muda a realidade. Você vai debater de frente com um médico ou não? Então assim, a gente questionava, debatia bastante, foi bem bom porque a gente ouvia coisas e elas ouviam o que a gente falava também, porque às vezes foge um pouco da realidade. Um pouco é estar lá dando aula, explicando um assunto que tem que ser isso e pronto. E tu ires pra prática e tu veres que não é assim... tem coisa que tu podes botar em prática, mas tem coisa que tu não podes botar em prática. Então é o que... ter bastante gente debatendo, conversando, foi bem interessante. (T II-4).

Outras dizem que não há espaço para esses comentários, os cursos são mais de conteúdos e os comentários ocorrem mais nos intervalos, na hora do café. Uma enfermeira sugere que se deveria discutir mais as dificuldades encontradas no cotidiano para a realização dos procedimentos aprendidos, talvez em grupos menores, para não "virar bagunça”. Por exemplo, dividir por Regionais de Saúde. E outras entendem que os problemas da unidade não devem ser revelados nos cursos, devem ser discutidos internamente, e então a enfermeira levar as questões para a Coordenação da Atenção Básica da Secretaria Municipal de Saúde, na ocasião das reuniões mensais que esta coordenação tem com as coordenadoras de UBS.

Não, a gente está ali focado em aprender a usar o ambú, a massagem, o que fazer. Então não tem, assim, são professores, que eles são muito bons e a gente quer aprender, relembrar, aprimorar, melhor de dizer. Então, nesses cursos não, até porque nós não teríamos porque falar para eles se eles não fazem parte, não são nossos gestores. Eles são pagos para dar aquele curso para nós. Então o momento de falar é nas nossas reuniões mensais, que são com os nossos gestores. Ali sim, a gente tem que falar e eu penso que as colegas não falam. (E-9).

Isso seria antiético e não resolutivo, pois nos cursos não se resolverá as questões e elas precisam ser levadas para quem pode resolvê-las.
[...] tu não podes: 'Ah, não tem isso, tão tem aquilo, como é que eu vou fazer'. Não, tu estás lá para aprenderes como é que tu vais fazer. Para te reciclares, tu não podes falar para reclamar determinadas coisas, o lugar está errado, isso tu tens que dirigir a outro local. Uma reunião, que é feita na reunião dos enfermeiros, é lá que tu tens que questionar essa parte e não em outra instituição. O outro local é feito para passarem o conhecimento e tu receberes e discutires as tuas dúvidas. (E-10).

Uma enfermeira conta que fez uma avaliação por escrito de que os profissionais ministrantes deveriam ter "experiência na ponta", ou seja, no trabalho na UBS, e não só conhecimento teórico. Esta fala expressa o distanciamento entre a fala do ministrante do cotidiano do trabalho dos profissionais. E esta aproximação é fundamental para que haja uma aprendizagem significativa. No entanto, mais do que a falta de experiência do ministrante em UBS, esta situação indica a falta de trocas no curso, pois não necessariamente todos os ministrantes tenham que ter a mesma experiência dos profissionais, eles poderão trocar suas experiências se houver esta possibilidade ou, na perspectiva freireana, se houver diálogo.

Outra enfermeira pontua que alguns cursos não foram bons, que se deve pensar que "[...] nós também somos profissionais, que nós somos pós-graduados, que temos alguma experiência, que trabalhamos aqui, que sabemos das coisas também" (E-9).

Nesse ponto foi perceptível o cuidado da maioria das profissionais em emitir uma opinião, ao relatarem casos em que houve, nos cursos, falas de profissionais revelando descontentamento com sua situação laboral. Mesmo que estes momentos tenham existido, o que prevalece é a compreensão de que os cursos são lugares de atualização de conteúdos e práticas. As trocas mencionadas vão mais na direção de apontarem o que podem ou não realizar do aprendido em suas unidades, não no sentido de problematizar os motivos pelos quais não podem realizar, o que falta - em termos de estrutura de tempo -, os motivos desta falta, problematizando, enfim, seu processo de trabalho. Neste sentido, as vivências cotidianas são colocadas, algumas vezes se socializam as vivências alternativas (o saber do cotidiano) - o que é acatado pelos ministrantes -, 
mas o que prevalece é o reforço da maneira correta de se atuar, mesmo tendo em vista o contexto desfavorável, talvez por esta reflexão não ser compreendida como foco do conteúdo a ser ministrado.

Sim, era tudo colocado, as experiências. No caso, ia lá, fazia o procedimento e cada um colocava a sua experiência, e com isso a gente absorvia conhecimento. Não só com o que estava ali, que era o tipo de curativo. Mas elas também colocavam outros tipos de curativos, dai a professora via e explicava pra gente também, não era só o que estava ali, o que eles estavam apresentando. (T I-4).

Porque, assim, esses cursos, eles trazem muito, eles focam o que o Ministério exige, mas não é a nossa realidade, nem tudo o que o Ministério exige é a nossa realidade. Então, acho que eles deveriam olhar um pouquinho isso. (T I-4).

Aqui aparece a sensação de que são cobradas coisas que não se tem a condição de fazer, o que também foi sinalizado por outra técnica. Isto, entretanto, não é colocado no curso, a técnica expõe para a enfermeira nas suas reuniões internas semanais e esta coloca na sua reunião mensal na Secretaria de Saúde.

Também merece registro uma situação de debate, que demonstra o empenho da ministrante do curso em fazer valer os direitos das profissionais, e o descrédito delas de sua possibilidade:

[...] ela [a ministrante do curso] disse que a gente pode estar debatendo, mostrar para o médico, dizer:

'Olha, eu fiz um curso de curativo, eu acho que fazendo isso, isso e aquilo outro tem como resolver'.

'Eles vão ter que ouvir vocês, não é obrigado, mas vocês como técnicas e ele como médico, vocês vão ter que entrar num conceito, porque vocês vão ter o que argumentar para ele, então vocês podem estar fazendo isso'. (T II -4).

Nesse caso, a técnica conta o debate que houve entre a ministrante, dizendo às técnicas que elas podiam se contrapor aos médicos, e outra técnica insistindo que isto era impossível. Ela mesma conclui o relato dizendo: "Então, assim, são coisas que a gente sabe que, nossa, quando que um técnico vai bater de frente com um médico, está fora de cogitação isso dai'". (T II-4).

Algumas fazem referência aos espaços formativos em sua UBS, para onde levam aquilo que aprenderam nos cursos e onde também têm liberdade de discutir os problemas internos. Uma delas reconhece esta ação também como formativa, o que está de acordo com a PNEPS, e a prioriza, dizendo que esta é mais importante, pois é de conteúdo relacional entre a equipe, não técnico. É a mesma enfermeira - e única - que reconhece conceitualmente a diferença entre EC e EP e identifica as capacitações recebidas como EC, tendo em vista serem de temas pontuais. Em vários relatos há a referência que, antes, se tinha livre toda uma tarde para irem à universidade fazer o curso, agora só têm as duas horas semanais que a UBS fecha para se reunirem e poderem discutir os casos ocorridos. Além de ser pouco tempo, há o transtorno do telefone que não para de tocar e dos usuários que ficam batendo na porta para serem atendidos.

\section{Considerações finais}

Percebe-se que as chamadas capacitações, em sua maioria, são pontuais, com assuntos voltados para atualização ou mesmo para facilitar o cumprimento das metas estabelecidas, como no caso das campanhas de vacinação. Existe espaço para discussão, para participação, mas esta parece ser entendida como manifestação de dúvidas e trocas de experiências, sem que esteja presente o elemento da reflexão crítica sobre o cotidiano do trabalho realizado, que parece ocorrer em algumas situações, mas nitidamente em menor número. Todavia, todas as profissionais disseram que os cursos são bons e que precisam continuar, para que possam atualizar-se. Poucas também apontaram que alguns cursos não são válidos.

Não desconsideramos a importância das atualizações profissionais, o que implica em que sejam trazidos assuntos técnicos. Contudo, então nos lembremos de que a relação entre profissional e usuário também envolve uma tecnologia, a tecnologia branda nomeada por Merhy. Isto não significa que não devam ter lugar cursos sobre tecnologias duras ou brandas-duras. Mesmo sendo este o foco de uma formação, se ela for pautada pela EPS, ela será problematizadora, crítica. O que caracteriza a EPS e a ECS não é o conteúdo foco, mas sim a abordagem na qual ele é tratado, e também a relação estabelecida entre ministrante e aluno (tecnologia 
branda!). Como diz Freire (2005), pode-se falar sobre qualquer assunto, o importante é a abordagem educativa que o envolve.

Outro ponto de relevância dos dados encontrados é a divergência entre as diretrizes dos programas do SUS e os serviços prestados à população, e a formação oferecida aos profissionais. As diretrizes do Ministério da Saúde em relação à ESF e à EPS têm como foco a promoção da saúde, o controle social, entre outros, mas ocorre uma distorção, uma inversão quando as ações são efetivadas, pois seu foco ainda está na assistência curativa e na produção de procedimentos a serem executados. As discussões a partir do cotidiano dos serviços não é a tônica da formação em serviço e, quando estão presentes, se direcionam à orientação de como viabilizar as ações preconizadas em meio às situações concretas, as quais, muitas vezes, não possibilitam sua efetivação. É raro ocorrer uma problematização da realidade vivenciada para subsidiar ações de transformação da realidade. Assim, podemos pensar que também a ação dos profissionais com a população não prioriza sua autonomia, mas sim a orientação de como proceder para combater e prevenir a doença.

Uma questão central que emerge dos dados é a lógica empresarial na qual o serviço público de saúde está inserido, que precisa ser questionada, tanto na EPS, como pelos órgãos gestores do setor. Este "excesso de papel", de relatórios comprovatórios de "produção", tão definidor da sociedade capitalista, tem a força avassaladora de marginalizar o humano em detrimento da máquina, a qual gira cada vez mais rápido. Se o SUS preconiza um conceito ampliado de saúde, com certeza a inserção dos serviços neste contexto desfavorece ações que a possam promover, tanto em relação aos usuários, como aos profissionais de saúde, que pedem socorro diante do excesso de atividades e da pressão no trabalho. Entretanto isto não é problematizado na sua formação em serviço.

Retomando a questão central deste texto - em que medida a formação em serviço dos profissionais de saúde da ESF possibilita sua viabilização enquanto pessoas críticas, autoras de suas práticas no seu processo de trabalho? - podemos afirmar que esta formação não a viabiliza, constituindo-se em uma educação continuada, de características bancárias, que não faz emergir a vontade de construir a mudança, que não produz sentido, conforme defendem Merhy, Feuerwerker e Ceccim (2006). A liberdade não é vivida como tal, vive-se uma alienação da liberdade, a falta da dimensão de que o indivíduo constrói sua história e constrói a história coletiva, e que estas histórias não estão determinadas. Perde-se, assim, o engajamento próprio da liberdade.

No entanto, sabemos que a história não deixa de ser escrita só porque seus "escritores" estão alienados desta sua dimensão, assim com a liberdade e o engajamento não desaparecem só porque as pessoas não se vivenciam como tal. Da mesma forma o "ser mais" não desaparece enquanto possibilidade somente porque não é possibilitado nas condições concretas de existência. O que se necessita é que esta dimensão do humano seja resgatada, e um dos instrumentos para tal é a educação libertadora, aproximada aqui da EPS. Outra necessidade seria resgatar o que já se tem produzido academicamente e preconizado legalmente e ir concretizando a transformação social necessária para produzir pessoas com autonomia, espírito coletivo e uma sociedade participativa. E também se faz necessária a opção política de utilizar o que já está produzido, pois o problema que se coloca não é a falta de conhecimento crítico ou mesmo de legislações avançadas. Eles existem. O que falta é a ação política - engajada - para concretizá-los. E esta ação implica em condições concretas para efetivar-se, tanto no âmbito singular/pessoal, como no geral/estrutural.

\section{REFERÊNCIAS}

BRASIL. Ministério da Saúde. Portaria no 1.996, de 20 de agosto de 2007. Dispõe sobre as diretrizes para a implementação da Política Nacional de Educação Permanente em Saúde e dá outras providências. Brasília, DF, 2007. Disponível em: <http://bvsms.saude.gov.br/bvs/saudelegis/gm/2007/prt1996_20_08_2007.html>. Acesso em: 01 set. 2015.

Ministério da Saúde. Portaria n⿳0 278, de 27 de fevereiro de 2014. Institui diretrizes para implementação da

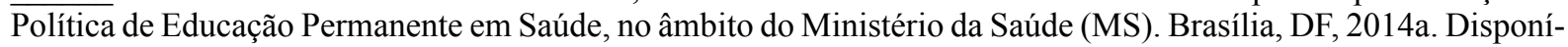


vel em: <http://bvsms.saude.gov.br/bvs/saudelegis/gm/2014/prt0278_27_02_2014.html>.Acesso em: 01 set. 2015.

. Ministério da Saúde. Secretaria-Executiva. Subsecretaria de Assuntos Administrativos. Educação Permanente em Saúde: um movimento instituinte de novas práticas no Ministério da Saúde: Agenda 2014. Brasília, DF: Ministério da Saúde, 2014b.

CECCIM, Ricardo B.; FEUERWERKER, Laura C.M. O quadrilátero da formação para a área da saúde: ensino, gestão, atenção e controle social. Physis, v. 14, n. 1, p. 41-65, 2004. Disponível em: <http://www.scielo.br/pdf/ physis/v14n1/v14n1a04.pdf>. Acesso em: 25 nov. 2009.

EAGLETON, Terry. Marx e a liberdade. São Paulo: Editora UNESP, 1999.

FREIRE, Paulo. Pedagogia do oprimido. 48. ed. Rio de Janeiro: Paz e Terra, 2005.

GOIS, Cléa. Sartre: da consciência do ser e o nada ao existencialismo humano. Reflexão, Campinas, SP, v. 32, n. 91, p. 11-17, jan./jun. 2007. Disponível em: $<$ http://periodicos.puc-campinas.edu.br/seer/index.php/reflexao/article/ view/3067/2033>. Acesso em: 30 jul. 2015.

HILGERT, Luiza Helena. Engajamento e literatura em Sartre. In: SIMPÓSIO DE FILOSOFIA MODERNA E CONTEMPORÂNEA DA UNIOESTE, 16., 2011, Toledo. Anais eletrônicos... Toledo: Unioeste, 2011. p. 290-297. Disponível em: $<$ http://projetos.unioeste.br/cursos/toledo/filosofia/attachments/article/222/Simp\%C3\%B3sio\%20 2011\%20-\%20Textos\%20Completos.pdf>. Acesso em: 30 jul. 2015.

MERHY, Emerson Elias; FEUERWERKER, Laura C. M.; CECCIM, Ricardo B. Educación Permanente en Salud: una estrategia para intervenir en la micropolítica del trabajo en salud. Salud Colectiva, Buenos Aires, v. 2, n. 2, p. 147-160, 2006. Disponível em: <http://www.redalyc.org/articulo.oa?id=73120204>. Acesso em: 14 ago. 2015.

MOREIRA, Janine; ROSA, Marisa de S. T. Jean-Paul Sartre e Paulo Freire: aproximações entre a liberdade existencialista e a educação libertadora. Revista Contrapontos, Itajaí, SC, v. 14, n. 3, p. 407-424, 2014. Disponível em: <http://www6.univali.br/seer/index.php/rc/article/view/5276/pdf_44>. Acesso em: 14 ago. 2015.

MORRIS, Katherine. J. Sartre. Trad. Edgar da Rocha Marques. Porto Alegre: Artmed, 2009.

MOUTINHO, Luiz D. Santos. Sartre: existencialismo e liberdade. São Paulo: Moderna, 2001.

SARTRE, Jean-Paul. O existencialismo é um humanismo. Petrópolis, RJ: Vozes, 2010. (Coleção Textos Filosóficos). O ser e o nada. 20. ed. Petrópolis, RJ: Vozes, 2011.

WAMBIER, Josiane de Fátima. A liberdade em Sartre: unidade entre projeto e engajamento. Emancipação, Ponta Grossa, PR, v. 3, n. 1, p. 41-54, 2003. Disponível em: <http://www.revistas2.uepg.br/index.php/emancipacao/article/ view/38/35>. Acesso em: 30 jul. 2015.

Recebido: 29/09/2015

Aprovado: 09/09/2017 